\title{
Common Venous Variations on Abdominal Multislice Computed Tomography
}

\section{Abdominal Çok Kesitli Bilgisayarlı Tomografide Saptanan Venöz Varyasyonlar}

\author{
Nuri Havan ${ }^{1 *}$ \\ ${ }^{1}$ Kartal Koşuyolu High Speciality Training and Research Hospital, Radiology Department, İstanbul, Turkey \\ * Corresponding author: Nuri Havan E-mail: nurihavan@hotmail.com ORCID: 0000-0003-1462-5012 \\ Received: 2 March 2019 Accepted: 18 May 2019
}

\begin{abstract}
Purpose: To determine the distribution of the types of variations in the portal vein and vena cava inferior and its branches using advanced image processing techniques in contrast enhanced abdominal multislice computed tomography (MSCT) examinations.

Methods: The study included 471 patients, comprising 254 males (53.9\%) and 217 females (46.1\%) with a median age of $53.7 \pm 16.1$ years, who underwent abdominal MSCT between April 2011 and December 2017.

Results: Of 471 patients, 2 patients ( $0.4 \%)$ had variation of the inferior vena cava, 122 patients ( $25.9 \%)$ had variation of the hepatic vein, 162 patients (34.4\%) had variation of the renal vein and 138 patients (29.3\%) had variation of the portal vein.

Conclusion: It is of great importance to use MSCT prior to surgical procedures such as transplantation, in which vascular variations are predetermined, and to pay attention to variations during reporting of the examination.
\end{abstract}

Keywords: abdominal vein variation, anatomy, hepatic vein, renal vein 


\section{ÖZ}

Amaç: Çalışmamızın amacı rutin intravenöz kontrastlı abdominal çok kesitli bilgisayarlı tomografi (ÇKBT) incelemelerinde portal venöz sistemde, vena kava inferior ve dallarında varyasyon tiplerinin dağılımını ileri görüntü işleme teknikleri kullanarak belirlemektir.

Gereç ve Yöntem: Çalışmaya Nisan 2011-Aralık 2017 arasında abdominal ÇKBT çekilen ortalama yaşları 53,7 \pm 16,1 olan 254 erkek (\%53,9), ve 217 kadın $(\% 46,1)$ olmak üzere toplam 471 hasta dahil edildi.

Bulgular: 471 hastanın 2'sinde $(\% 0,4)$ inferior vena kana varyasyonu, 122'sinde $(\% 25,9)$ hepatik ven varyasyonu, 162 'sinde $(\% 34,4)$ renal ven varyasyonu ve 138 hastada $(\% 29,3)$ da portal ven varyasyonu mevcuttu.

Sonuç: Özellikle vasküler varyasyonların önceden bilinmesinin gerektiği transplantasyon gibi cerrahi işlemlerden önce abdominal ÇKBT çekilmesi ve raporlama sırasında varyasyonlara dikkat edilmesi çok önemlidir.

Anahtar kelimeler: abdominal venöz varyasyonlar, hepatik ven, portal ven, inferior vena kava, renal ven, çok kesitli bilgisayarlı tomografi

\section{INTRODUCTION}

Venous system variations are more common than other vascular variations [1]. Knowing the presence and course of variations in the venous system in the preoperative period reduces the complications that may occur during abdominal surgery operations and increases the success of the operation $[2,3]$.

Advances in radiological imaging systems together with technological advances have led to the evaluation of vascular structures with non-invasive methods. Computed tomography $(\mathrm{CT})$ has a particularly important role in noninvasive imaging of the vascular system [4]. As a consequence of these technological developments, multislice computed tomography (MSCT) can be used to evaluate the vascular system in a more detailed, easy and accurate way with post-process processes such as multiplanar reconstruction (MPR), volume rendering (VR), and maximum intensity projection (MIP) [5].

The aim of this study was to determine the distribution of the types of variations in the portal vein and vena cava inferior and its branches using advanced image processing techniques in contrast enhanced abdominal multislice computed tomography (MSCT) examinations.

\section{MATERIALS AND METHODS}

\section{Ethics}

This retrospective study was approved by the Local Ethics Committee and was conducted in accordance with the Declaration of Helsinki (2000). Informed consent was waived because of the retrospective nature of the study.

\section{Patients}

Between April 2011 and December 2017, 593 patients underwent abdominal MSCT. A total of 122 patients were excluded from the study as optimal contrast enhancement of CT was not achieved. As a result, the study included 471 patients comprising 254 males (53.9\%) and 217 females $(46.1 \%)$ with a median age of $53.7 \pm 16.1$ years. The CT images of all the patients were retrospectively reviewed.

\section{CT Technique}

Abdominopelvic CT imaging was applied with a 128 detector CT (Toshiba Aquillion CX MDCT, Nasu Shiobara, Japan) scanner. One hundred milliliters $(\mathrm{ml})$ of intravenous (IV) contrast material (lopromid, 370/100 m/L Ultravist ${ }^{\circledR}$, Bayer Schering Pharma AG, Germany) at a flow rate of 4 $\mathrm{ml} / \mathrm{sec}$ was used in the CT examinations. No oral contrast material was given. The venous phase abdominal CT scans (tube voltage $=120 \mathrm{kV}$, effective $\mathrm{mAs}=50-300$, slice thickness $0.5 \mathrm{~mm}$, collimation $=64 \times 0.5 \mathrm{~mm}$, pitch $=0.8$ ) were acquired 65 seconds after the IV contrast injection. The abdominal CT scan area included the body region from the level of the upper diaphragm to the ischial tubercles.

\section{Image Analysis}

The CT images were reviewed retrospectively by a radiologist with 5 years of experience in abdominal radiology, who was blinded to the physical examination findings, laboratory results, and radiology reports.

The CT images were evaluated on axial, coronal and sagittal planes using the post-processing applications of MPR, VR and MIP on the workstation (Shina 2010, Caesarea, Israel). 


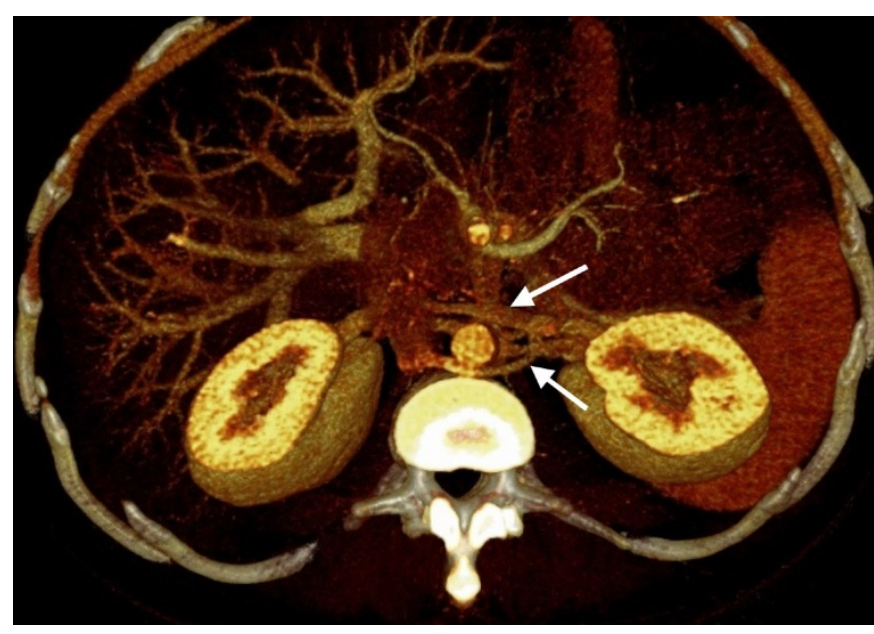

Figure 1. Axial VR image showing type 2 (circumaortical renal vein) renal vein anomaly (arrows)

MIP and MPR were used for the evaluation of intraparenchymal veins, especially the portal vein and hepatic vein. In general, an average thickness of $15 \mathrm{~mm}$ was used. VR images were preferred in the evaluation of extraparenchymal venous structures and especially in renal veins and variations.

The data were analyzed in three categories: portal venous system, hepatic venous system, IVC and its branches. During examination of the portal system, the normal anatomic configuration of the portal vein and variations of main branches were investigated. In the evaluation of the hepatic venous system, variations in the main hepatic veins, differences in branching and expansions of IVC in hepatic veins were evaluated. Vascular relationships were evaluated in the area near the hepatic vein-IVC junction area (confluence) at a distance of 1 centimeter. Vascular structures more than $1 \mathrm{~cm}$ away from the confluence were evaluated in the branching configurations of the hepatic vein. The renal vein and its variations were investigated in the evaluation of IVC and its branches. The incidence of testicular and ovarian veins to the right renal vein was also evaluated. In addition, the distribution of the described variations according to gender and the possibility of an additional variation in the presence of venous variation were compared according to the frequency of normal venous variations in the population.

\section{Statistical Analysis}

Statistical Package for Social Sciences (SPSS) version 20.0 software (Chicago, IL, USA) was used for statistical analysis. Descriptive statistics were given as median (minimum maximum) and mean \pm standard deviation. The Chi-square test was used to compare categorical data between male and female groups. The relationships between the

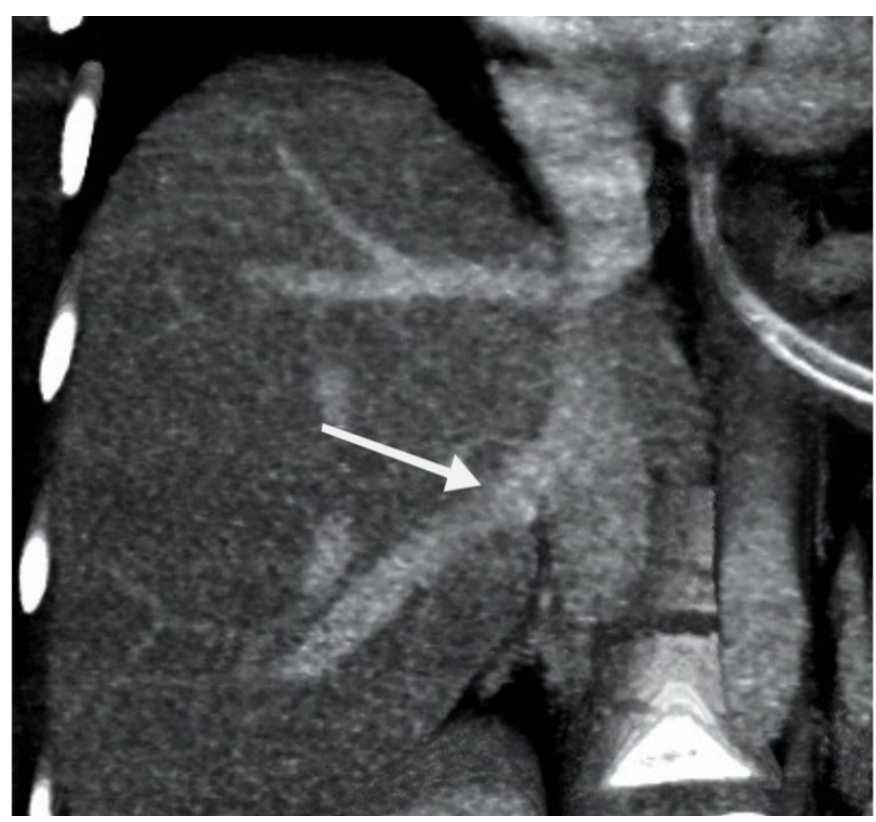

Figure 2. Type 2 (inferior right hepatic vein) hepatic vein variation is seen on the coronal inferior oblique VR image (arrow)

parametric data were investigated using Pearson correlation analysis. Statistical significance was accepted at the value of $p<0.05$.

\section{RESULTS}

At least one venous variation was detected in 388 patients (72.4\%). In 471 patients, inferior vena cava (IVC) variation was observed in $2(0.4 \%)$ patients. In these 2 patients, there were type 3 IVC (double IVC) and no patients had type 2 (leftsided IVC) variations.

Renal vein variation was detected in 127 patients (26.96\%), of which 22 patients (4.7\%) had type 2 (circumaortical renal vein) (Figure 1), 20 patients (4.3\%) had type 3 (retroartic renal vein) and 68 patients (14.4\%) had type 4 (double or more renal veins) renal vein variation. Type 5 (type $2+$ type 4) variation was observed in 8 patients (1.7\%) and type 6 (type $3+$ type 4 ) in 9 patients (1.9\%). Renal venous variation was higher in females than males $(p=0.044)$.

Hepatic vein variation was detected in 122 patients (25.9\%). The most frequently observed variation was type 2 (Figure 2). 87 patients (18.5\%) had type 2 (inferior right hepatic vein), 13 patients (2.8\%) had type 3 (same level anterior and posterior hepatic vein), 12 patients (2.5\%) had type 4 (different level anterior and posterior hepatic vein), 3 patients $(0.6 \%)$ had type 5 (accessory vein (tributary vein) to medium hepatic vein), 3 patients $(0.6 \%)$ had type 7 (more than 2 hepatic veins at the same level) and 1 patient $(0.2 \%)$ had type 8 (more than 2 hepatic veins at different levels) hepatic vein variation. None of the patients had type 6 (one, two or more right hepatic vein branches) hepatic vein 
variation. Hepatic vein variations were also observed more frequently in females, similar to the renal vein $(p=0.039)$.

Portal vein variation was determined in 138 patients (29.3\%). 57 patients $(12.1 \%)$ had type 2 (trifurcation), 65 patients (13.8\%) had type 3 (the right anterior portal vein and the left portal vein together form a common branch), 8 patients (1.7\%) had type 4 (separate opening of the 6 th and / or 7th segment branch) portal vein anomalies. No statistically significant difference was found between the genders in portal vein variations $(p=0.065)$.

\section{DISCUSSION}

In this study, at least one venous variation was detected in 388 patients (72.4\%). In a study conducted by Koc et al., this rate was found to be $67.5 \%$ [6]. IVC variation was found in 2 patients (0.42\%). Type 3 IVC anomaly (double IVC) was present in these 2 patients. In the Koc et al. study, the prevalence of type 3 IVC was found to be $0.2 \%$ [6]. In a study by Boyaci et al., the prevalence of IVC variation was found to be $0.3 \%$ [7]. In a study by Dilli et al using lumbar MRI images, the prevalence of IVC variation was found to be $0.07 \%$ [8]. This difference may be related to the evaluation of MRI images, not $\mathrm{CT}$, in the above-mentioned study. Double IVC anomaly should be investigated especially in patients with recurrent embolism. It should also be kept in mind that it may cause technical difficulties during the insertion of the IVC filter [9].

In the current study, renal vein variation was detected in 127 patients (26.96\%). The most common variation was type 4 (double or more renal veins) detected in 68 patients (14.4\%). In a study conducted by Koc et al., $24.4 \%$ of patients had renal vein variations. Similar to the current study, the most common variation was reported as type 4 and renal vein variations were found to be more common in females [6]. Chai et al. compared renal vein variations detected on CT with the surgical findings in patients who underwent $C T$ before donor nephrectomy and only 2 of 153 cases had incompatibility [10]. Knowledge of renal vein anomalies is especially important in retroperitoneal surgery as they can cause complications such as bleeding, nephrectomy and even death $[11,12]$. In renal transplant donors, the left side is preferred because of the longer length of the left renal vein. Therefore, it is important to know whether the left renal vein has a normal pre-aortic course [13].

Hepatic vein variation was detected in 122 patients (25.9\%). The most frequently observed variation was type 2 and was the inferior right hepatic vein (IRHV) anomaly, also known as caudal hepatic vein. 87 patients (18.5\%) had type 2 hepatic vein variations. Although the prevalence of hepatic vein variation has been reported as $86 \%$ in autopsy studies [14], this rate varies between $9-67 \%$ in imaging-based studies [15-17]. The reason for this difference may be that below a certain diameter, visualization cannot be determined by imaging. In the study by Koc et al., $41.8 \%$ of the patients had hepatic vein variation. Similar to the current study, the most common subtype was reported as type 2 [6]. The hepatic venous anatomy is important because it determines the anatomic structure of the liver. Identification of the location and variations of the preoperative hepatic veins is clearly important in terms of planning the surgery and reducing possible complications [18]. If accessory hepatic veins above $3 \mathrm{~mm}$ are not detected before the operation and if they are not reconstructed in the operation, congestion and liver failure may develop in the graft through venous drainage obstruction $[18,19]$. Even small hepatic veins seen on the dissection line in liver resections may cause graft congestion and may be the cause of insufficiency unless properly reconstructed [20].

Portal vein variation was determined in 138 patients (29.3\%). The most common subtype was type 3 (the right anterior portal vein and the left portal vein together form a common branch) portal vein seen in 65 patients (13.8\%). In previous studies, the rate of variation in studies using spiral CT has been found to be $6-13 \%[21,22]$, while studies using MSCT have reported rates of $20-29 \%[19,18,23]$. The most important reason for this difference is the increase in the probability of variation as the section thickness decreases. Koc et al. found portal vein variation in $27.4 \%$ of patients, with no difference between the genders, similar to the current study. However, unlike the current study, the most frequent type reported was type 2 (trifurcation) [6]. There are some benefits in terms of operative and preoperative identification of portal variations. Sometimes, anatomic variations in the portal venous system create a contraindication to surgery or complicate surgery or increase the risk of postoperative complications $[3,24]$. In the absence of the right portal trunk, the right lobe is fed with more than one vein (Type 3 variation) originating separately from the main portal vein and / or the left portal vein. In this case, more than one portal vein anastomosis should be performed during transplantation, which increases both the duration of surgery and the risk of postoperative portal vein thrombosis [22].

This study had several limitations. First, only the imaging variables were evaluated and the clinical and laboratory data of patients were not taken into consideration. However, the primary aim of this study was to demonstrate the value 
of MSCT findings. Second, the nature of the study was retrospective. Third, there was no assessment of interobserver variability, although this could be a subject for further study.

In conclusion, it is of great importance to use MSCT prior to surgical procedures such as transplantation, in which vascular variations are predetermined, and to pay attention to variations during reporting of the examination.

\section{ACKNOWLEDGEMENTS}

I would like to thank to Dr. Murat Acar and Dr. Onur Taydaş who supported me during preparing this article.

\section{DECLARATION OF CONFLICT OF INTEREST}

The authors received no financial support for the research and/or authorship of this article. The author declared no conflicts of interest with respect to the authorship and/or publication of this article.

\section{REFERENCES}

1. Covey AM, Brody LA, Getrajdman Gl, Sofocleous CT, Brown KT. Incidence, patterns, and clinical relevance of variant portal vein anatomy. AJR Am J Roentgenol. 2004;183:1055-1064.

2. Madhusudhan KS, Vyas S, Sharma S, Srivastava DN, Gupta AK. Portal vein abnormalities: an imaging review. Clin Imaging. 2018;52:70-78.

3. Lee WK, Chang SD, Duddalwar VA, Comin JM, Perera W, Lau WF, Bekhit EK, Hennessy OF. Imaging assessment of congenital and acquired abnormalities of the portal venous system. Radiographics. 2011;31:905-926.

4. Fishman EK. From the RSNA refresher courses: CT angiography: clinical applications in the abdomen. Radiographics. 2001;21:3-16.

5. Duddalwar V. Multislice CT angiography: a practical guide to $\mathrm{CT}$ angiography in vascular imaging and intervention. The British Journal of Radiology. 2004;77:27-38.

6. Koc Z, Ulusan S, Oguzkurt L, Tokmak N. Venous variants and anomalies on routine abdominal multi-detector row CT. Eur J Radiol. 2007;61:267-278.

7. Boyaci N, Karakas E, Dokumaci DS, Yildiz S, Cece H. Evaluation of left renal vein and inferior vena cava variations through routine abdominal multi-slice computed tomography. Folia Morphol (Warsz). 2014;73:159-163.
8. Dilli A, Cosar Ayaz FS, Karacan K, Zengin K, Ayaz UY, Karabacak OR, Hekimoglu B. Evaluation of renal anomalies, inferior vena cava variations, and left renalvein variations by lumbar magnetic resonance imaging in 3000 patients. Turk J Med Sci. 2017;47:18661873.

9. Smillie RP, Shetty M, Boyer AC, Madrazo B, Jafri SZ. Imaging evaluation of the inferior vena cava. Radiographics. 2015;35:578-592.

10. Chai JW, Lee W, Yin YH, Jae HJ, Chung JW, Kim HH, Park $\mathrm{JH}$. CT angiography for living kidney donors: accuracy, cause of misinterpretation and prevalence of variation. Korean J Radiol. 2008;9:333-339.

11. Urban BA, Ratner LE, Fishman EK. Three-dimensional volume-rendered $C T$ angiography of the renal arteries and veins: normal anatomy, variants, and clinical applications. Radiographics. 2001;21:373-386; questionnaire 549-355.

12. Taydas O, Kantarci M, Bayraktutan U, Ogul $H$. Supradiaphragmatic origin of the renal artery; frequency on contrast-enhanced MR imaging. Clin Imaging. 2018;52:152-156.

13. Sahani DV, Rastogi N, Greenfield AC, Kalva SP, Ko D, Saini $S$, Harris G, Mueller PR. Multi-detector row CT in evaluation of 94 living renal donors by readers with varied experience. Radiology. 2005;235:905-910.

14. Champetier J, Haouari H, Le Bas JF, Letoublon C, Alnaasan I, Farah I. Large inferior right hepatic vein. Clinical implications. Surg Radiol Anat. 1993;15:21-29.

15. Kamel IR, Kruskal JB, Pomfret EA, Keogan MT, Warmbrand $\mathrm{G}$, Raptopoulos V. Impact of multidetector CT on donor selection and surgical planning before living adult right lobe liver transplantation. AJR Am J Roentgenol. 2001;176:193-200.

16. Akgul E, Inal M, Binokay F, Celiktas M, Aikimbaev K, Soyupak $S$. The prevalence and variations of inferior right hepatic veins on contrast-enhanced helical CT scanning. Eur J Radiol. 2004;52:73-77.

17. Soyer P, Bluemke DA, Choti MA, Fishman EK. Variations in the intrahepatic portions of the hepatic and portal veins: findings on helical CT scans during arterial portography. AJR Am J Roentgenol. 1995;164:103-108. 
18. Kamel IR, Kruskal JB, Keogan MT, Goldberg SN, Warmbrand G, Raptopoulos V. Multidetector CT of potential right-lobe liver donors. AJR Am J Roentgenol. 2001;177:645-651.

19. Guiney MJ, Kruskal JB, Sosna J, Hanto DW, Goldberg SN, Raptopoulos V. Multi-detector row CT of relevant vascular anatomy of the surgical plane in split-liver transplantation. Radiology. 2003;229:401-407.

20. Kruskal JB, Raptopoulos V. How I do it: pre-operative CT scanning for adult living right lobe liver transplantation. Eur Radiol. 2002;12:1423-1431.

21. Platt JF, Ellis JH, Korobkin M, Reige K. Helical CT evaluation of potential kidney donors: findings in 154 subjects. AJR Am J Roentgenol. 1997;169:1325-1330.
22. Mortele KJ, Cantisani V, Troisi R, de Hemptinne B, Silverman SG. Preoperative liver donor evaluation: Imaging and pitfalls. Liver Transpl. 2003;9:S6-14.

23. Sharma V, Chauhan R, Sood R, Makhaik S, Negi K, Chawla K, Diwan Y, Partap A, Rana S, Gupta A. Study of the normal anatomy and variations of portal vein in North Indian population: a MDCT study. Eur j anat. 2017;21:1318.

24. Schmidt S, Demartines N, Soler L, Schnyder P, Denys A. Portal vein normal anatomy and variants: implication for liver surgery and portal vein embolization. Semin Intervent Radiol. 2008;25:86-91. 